\title{
Cytotoxic Effect of Oxidized Low Density Lipoprotein on Macrophages
}

\author{
Hideki Hakamata, Akira Miyazaki, Masakazu Sakai, Yu-Ichiro Sakamoto, and Seikoh \\ Horiuchi
}

Department of Biochemistry and Department of Metabolic Medicine, Kumamoto University School of Medicine Kumamoto, Japan

\begin{abstract}
Macrophage or macrophage-derived foam cell death is one of the characteristic events in the development of cell-poor lipid-rich cores of the advanced atherosclerotic plaques. Although the in vivo mechanism for the death of macrophages is unclear, one possible candidate for the agent which induces macrophage cell death is oxidized low density lipoprotein (Ox-LDL). To investigate the mechanism of Ox-LDL-induced macrophage cell death, we have recently employed macrophage cell genetics and isolated mutant cells resistant to the cytotoxic effect of Ox-LDL from mutagenized populations of murine macrophage-derived J774 cells (Hakamata, H., Miyazaki, A., Sakai, M., Matsuda, H., Suzuki, H., Kodama, T., and Horiuchi, S. (1998) J. Lipid Res. 39, 482-494). The results obtained showed that one mutant form, J021b cells, was characterized by reduced expression of type I and type II class A macrophage scavenger receptors (MSR-Al/All) with a concomitant decrease in the uptake of Ox-LDL. Moreover, peritoneal macrophages obtained from MSRAl/All-knockout mice showed a higher resistance to the cytotoxic effect of Ox-LDL compared to those of their wild-type littermates. From these results, we have concluded that OxLDL cytotoxicity to macrophages is enhanced by effective endocytic uptake of Ox-LDL through MSR-AI/All. These findings imply a possibility that formation of the cell-poor lipidrich core is also enhanced by MSR-Al/All-mediated uptake of Ox-LDL and subsequent macrophage cell death in atherosclerotic lesions. J Atheroscler Thromb, 1998 ; 5 : 66 75.
\end{abstract}

Key words: Macrophage cell death, Oxidized LDL, Type I and type II class A macrophage scavenger receptors, Cell genetics

\section{Introduction}

Oxidatively modified low density lipoprotein (Ox-LDL) is

$\overline{\text { Address for correspondence: Seikoh Horiuchi, M.D., Ph.D., }}$ Department of Biochemistry, Kumamoto University School of Medicine, Hongo 2-2-1, Kumamoto 860-0811, Japan

E-mail : horiuchi@gpo.kumamoto-u.ac.jp

Abbreviations: LDL: Iow density lipoprotein, acetyl-LDL: acetylated LDL, Ox-LDL: oxidized LDL, CE: cholesteryl ester(s), MSR-AI/All : class A macrophage scavenger receptors, type I and type II, MTT : 3-(4, 5-dimethylthiazol-2-yl)2,5-diphenyltetrazolium bromide, NCS: newborn calf serum.

This state-of the-art minirevew is based on the article given the 1998 JAS Award for the Distinguished Atherosclerosis Research

Received September 21, 1998. generally accepted as a likely atherogenic lipoprotein in vivo (1). This is partly because Ox-LDL was demonstrated in human and rabbit atherosclerotic lesions $(2,3)$ and partly because various atherogenic properties of Ox-LDL have been demonstrated by in vitro experiments with vascular wall cells (4). Among these atherogenic properties, recent studies have shed light on the cytotoxic effect of Ox-LDL (5), because Ox-LDL-induced vascular cell death may enhance atherosclerotic lesion progression (6). In the current review, we focus on the cytotoxic effect of Ox-LDL on macrophages and their potential link to the progression of atherosclerosis.

\section{Formation of Early Atherosclerotic Lesions}

The appearance of lipid-laden macrophage-derived 


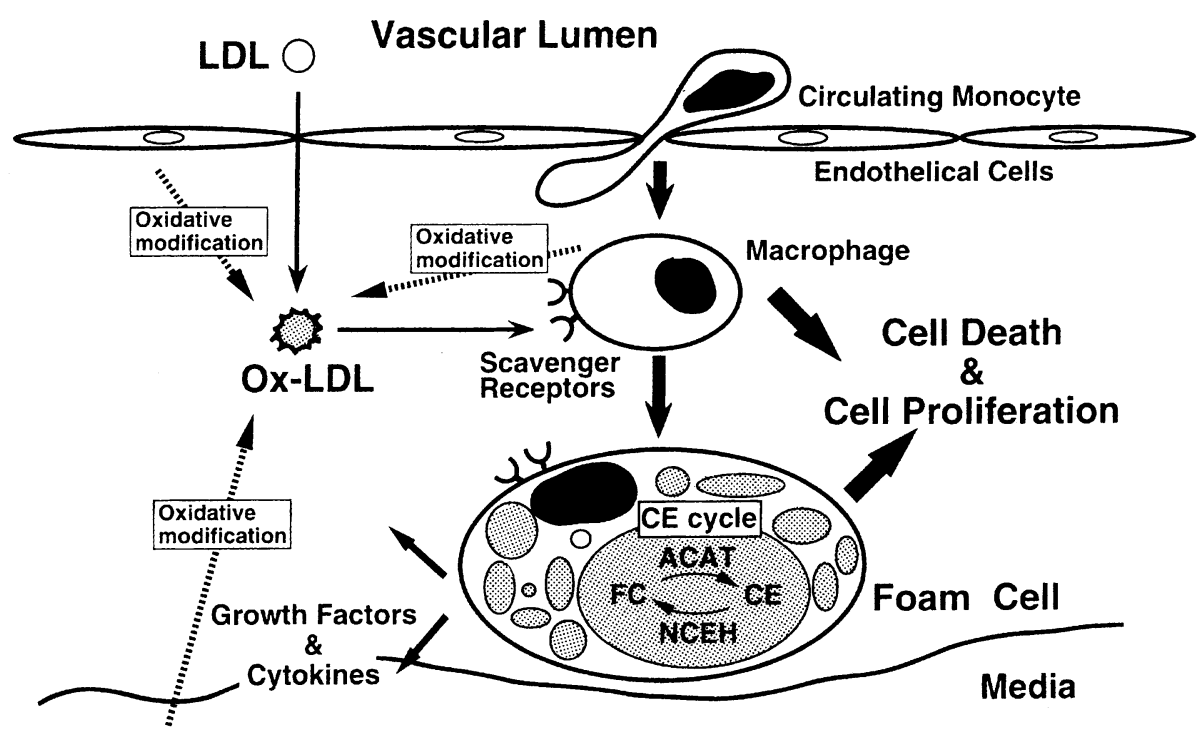

Fig. 1. Schematic representation of the formation of the early stage of atherosclerotic lesions or macrophage-derived foam cells.

foam cells is a typical characteristic of the early stage of atherosclerotic lesions (7). Fig. 1 shows a widely accepted mechanism for the formation of macrophage foam cells in vivo (1). Circulating monocytes adhere to vascular endothelial cells, transmigrate into subendothelial space, and differentiate into macrophages which express scavenger receptors. LDL is oxidatively modified by arterial cells such as vascular endothelial cells, smooth muscle cells and macrophages, and eventually acquires a ligand activity for scavenger receptors (1). Ox-LDL is taken up by macrophages through the scavenger receptor pathway $(1,8)$ followed by delivery through endosomes to lysosomes (9). In the lysosomes, the protein moiety of modified LDLs is subjected to proteolytic hydrolysis, whereas the cholesterol moiety, mainly $\mathrm{CE}$, is hydrolyzed to free cholesterol and fatty acids by acidic cholesteryl ester hydrolase (ACEH). Free cholesterol is then transported to plasma membrane (10) and is further delivered to the endoplasmic reticulum, where it is reesterified to $C E$ by acyl-coenzyme $A$ : cholesterol acyltransferase (ACAT) (11). Cellular CE undergoes continual hydrolysis to free cholesterol by neutral cholesterol ester hydrolase (NCEH) and subsequent re-esterification to CE by ACAT. This metabolic cycle is known as the cholesteryl ester cycle (CE cycle) $(12,13)$. Since macrophage foam cells are known to secrete various cytokines which trigger off further progression of atherosclerosis, formation of macrophage foam cells by the above mechanisms is regarded as a critical event in the lesion progression (7).

\section{Formation of Advanced Atherosclerotic Lesions}

In contrast to the early atherosclerotic lesions, atheros- clerotic plaques, more advanced lesions, are characterized by the presence of acellular lipid-rich cores (lipid cores) composed of extracellular lipid deposits and cell debris $(6,7,14)$. Extracellular lipids might partly derive from intracellular lipids released from dying or dead cells and might partly derive from plasma lipoproteins which was not taken up by cells because cells had been dead in the plaques. Therefore, cell death in atherosclerotic lesions is a key event for advanced lesion progression (6). Lipid cores are also called 'necrotic cores' due to the presence of dead cells. Among the various cells in vascular walls, immunohistochemical studies suggest that the major cell type dying in human atherosclerotic plaques is macrophages (15).

The atherogenic effects of Ox-LDL on macrophages include intracellular CE accumulation (1), chemotactic activity for monocytes (16), enhancement of monocyte adhesion to endothelial cells (17), initiation of monocyte differentiation into macrophages (18), and inhibition of tissue macrophage migration (19). Recent studies have also demonstrated macrophage cell death induced by $\mathrm{Ox}-$ LDL (20), which is a novel aspect of Ox-LDL atherogenicity. Taken together, elucidation of the mechanism for macrophage cell death by Ox-LDL may provide new mechanistic insights into the development of advanced atherosclerotic lesions.

\section{Cytotoxic Effect of Ox-LDL on Vascular Cells}

Although the mechanism of cell death in atherosclerotic lesions in vivo is still unclear, in vitro experiments have proposed that Ox-LDL is a possible candidate that induces cell death (5). As shown in Table 1, cytotoxicity of Ox-LDL was first reported in vascular endothelial cells 
Table 1. Cytotoxicity of Ox-LDL to Vascular Cells in vitro

\begin{tabular}{|c|c|c|c|c|c|}
\hline & Cell Types & Toxins & Serum & Authors & Journal \\
\hline \multirow[t]{8}{*}{ Endothelial Cells } & HUVEC & LDL & (free?) & Henriksen, et al. & Scad J Clin Lab Invest 39: 361-368, 1979 \\
\hline & HUVEC & LDL & (free?) & Bфrsum, et al. & Scad J Clin Lab Invest $42:$ 75-81, 1982 \\
\hline & BAEC & Ox-LDL & free & Kuzuya, et al. & BBRC 163: 1466-1472, 1989 \\
\hline & PAEC & Ox-LDL & free & Balla, et al. & Arteriosclerosis 11: 1700-1711, 1991 \\
\hline & BAEC & Ox-LDL & free & Kuzuya, et al. & BBA 1096: 155-161, 1991 \\
\hline & BAEC & Ox-LDL & $1 \%$ FCS & Thomas, et al. & JLR $34:$ 479-490, 1993 \\
\hline & BAEC & Ox-LDL & free & Naito, et al. & Heart Vessels 9: 183-187, 1994 \\
\hline & GM07372A & Ox-LDL & $2 \%$ Ultroser $\mathrm{G}$ & Shhmitt, et al. & BBA 1256: 284-292, 1995 \\
\hline \multirow[t]{3}{*}{ SMC } & HASMC & LDL & $10 \%$ LPDS & Hessler, et al. & Atherosclerosis $32:$ 213-229, 1979 \\
\hline & PASMC & Ox-LDL, oxysterol & $0.4 \%$ DLFCS & Hughes, et al. & AT $14: 1177-1185,1994$ \\
\hline & HASMC & Ox-LDL & free & Björkerud, et al. & ATVB $16: 416-424,1996$ \\
\hline \multirow[t]{9}{*}{ Macrophages } & MPM & Ox-LDL & $10 \%$ LPDS & Reid, et al. & Atherosclerosis $98: 17-24,1993$ \\
\hline & P388D1 & Ox-LDL & $10 \%$ LPDS & Reid, et al. & FEBS Lett 332 : 218-220, 1993 \\
\hline & HMM & Ox-LDL & $10 \%$ LPDS & Marchant, et al. & FEBS Lett 358: 175-178, 1995 \\
\hline & HMM & oxysterol & $10 \%$ LPDS & Clare, et al. & Atherosclerosis $118: 67-75,1995$ \\
\hline & THP-1 & Ox-LDL & free & Bjökerud, et al. & ATVB $16: 416-424,1996$ \\
\hline & J774, HMM & Ox-LDL & $10 \%$ FCS & Yuan, et al. & Atherosclerosis $133:$ 153-161, 1997 \\
\hline & P388D1 & oxysterol & & Harada, et al. & FEBS Lett $411: 63-66,1997$ \\
\hline & HMM & Ox-LDL & LPDS & Kinscherf, et al. & FASEB J $12: 461-467,1998$ \\
\hline & $\mathrm{J} 774$ & Ox-LDL & $10 \%$ NCS & Hakamata, et al. & JLR $39:$ 482-494, 1998 \\
\hline
\end{tabular}

Ox-LDL has been reported to be toxic to vascular endothelial cells, vascular smooth muscle cells (SMC) and macrophages. Although LDL was used instead of Ox-LDL as a toxin in several studies, it is expected that LDL was oxidatively modified to Ox-LDL by cells and showed cytotoxic effects. "Serum" indicates the concentrations of serum or serum-derived proteins in the medium.

SMC indicate smooth muscle cells; HUVEC, human umbilical vein endothelial cells; BAEC, bovine aortic endothelial cells ; PAEC, porcine aortic endothelial cells; GM07372A, bovine aortic endothelial cell-derived cell line; HASMC, human aortic smooth muscle cells; CASMC, canine aortic smooth muscle cells; PASMC, porcine aortic smooth muscle cells; MPM, murine peritoneal macrophages; P388D1, murine macrophage-like cell line, HMM, human monocyte-derived macrophages; THP-1, human monocytic leukemia-derived cell line ; J774, murine macrophage-like cell line ; FCS, fetal calf serum ; Ultroser G, a lipoprotein-free serum substitute (from IBF); LPDS, lipoprotein-deficient serum; DLFCS, delipidated FCS; NCS, newborn calf serum; BBRC, Biochemical and Biophysical Research Communications; BBA, Biochimica et Biophysica Acta; JLR, Journal of Lipid Research; AT, Arteriosclerosis and Thrombosis; and ATVB, Arteriosclerosis, Thrombosis and Vascular Biology.

$(21,22)$ and smooth muscle cells (22). Cytotoxicity of OxLDL to vascular smooth muscle cells is supposed to be involved in the formation of lipid cores in atherosclerotic plaques (23). In contrast to these two types of cells, researchers in this field did not pay much attention to the cytotoxic effect of Ox-LDL on macrophages. However, in 1990's, it was demonstrated by several independent groups (Table 1). These studies emphasized that apoptosis is a major mechanism of Ox-LDL-induced macrophage cell death. Reid et al. (24) showed that exposure of $\mathrm{P}_{388 \mathrm{D}_{1}}$ murine macrophage-like cells to $\mathrm{Ox}$ LDL led to DNA fragmentation which is often used as a biochemical marker of apoptosis. Using the same cell line, Harada et al. (25) showed that 7-ketocholesterol or 25-hydroxycholesterol induced apoptosis partly through a CPP32-activated and Bcl-2-inhibitable pathway. Yuan et al. (26) suggested that the apoptosis induced by OxLDL is due to lysosomal damage in $\mathrm{J774}$ macrophages. Recently, Kinscherf et al. (27) showed that manganese superoxide dismutase and p53 play essential roles in the Ox-LDL-induced apoptotic cell death of human monocyte-derived macrophages.

Since macrophage apoptosis is observed in lipid cores of the human atherosclerotic lesions (14), Ox-LDL-induced macrophage apoptosis is a likely mechanism for macrophage cell death in the atherosclerotic lesions. However, despite our electron microscopic observations of $\mathrm{J} 774$ cells, we were unable to detect typical morphological features of apoptosis such as condensation of nuclear chromatin, the compact cytoplasmic organelles, and the blebbing of cell surfaces. Thus, Ox-LDL seems to lead macrophages to "necrosis" as well as "apoptosis."

One thing worth mention in this review is that the cytotoxicity of oxidized LDL in vitro is altered by the presence of serum components in the medium. In general, serum proteins reduces Ox-LDL cytotoxicity in cell culture. Lipoproteins in serum could adsorb cytotoxic polar lipids in Ox-LDL. Some serum proteins may behave as anti-oxidants. Moreover, serum contains growth factors which rescue cell viability. As shown in Table 1, some experiments were conducted under conditions too harsh to cells (e.g.. in serum-free medium). Since the concen- 
trations of serum components in atherosclerotic plaque cores are unclear, careful interpretations of these in vitro experiments are needed.

\section{A Somatic Cell Genetic Approach to Ox-LDL-Induced Macrophage Cell Death}

Isolation of macrophage-like cell mutants resistant to the cytotoxicity of Ox-LDL

In order to obtain molecular insights into the mechanisms involved in macrophage cell death by Ox-LDL, we made a macrophage cell genetic approach (28). Murine macrophage-like $\mathrm{J} 774$ cells were mutagenized with ethylmethane sulfonate and exposed to a lethal concentration of Ox-LDL $(0.1 \mathrm{mg} / \mathrm{ml})$. Then, resistant clones were selected. One mutant form, named JO21b cells, was characterized by molecular and cell biological methods. When assessed by MTT (3-(4, 5-dimethylthiazol-2-yl)-2, 5-diphenyltetrazolium bromide) assay, cell viability of J774 cells was decreased almost to a basal level by 7 day incubation with $0.1 \mathrm{mg} / \mathrm{ml}$ of $\mathrm{Ox}-\mathrm{LDL}$, indicating that $\mathrm{J} 774$ cells were sensitive to the cytotoxic effect of OxLDL (Fig. 2B). At the same concentration, however, OxLDL had no effect at all on the cell viability of JO21b cells, indicating resistance of $\mathrm{JO} 21 \mathrm{~b}$ cells to the cytotoxic effect of Ox-LDL (Fig. 2A). Acetyl-LDL exhibited no cytotoxic effect on JO21b cells or J774 cells (Fig. 2A and B). Rather, it showed a weak stimulating effect on the cell viability. The viability of these cells was not influenced by unmodified LDL, suggesting that the cytotoxic effect of Ox-LDL on J774 cells was selective among these LDL preparations.

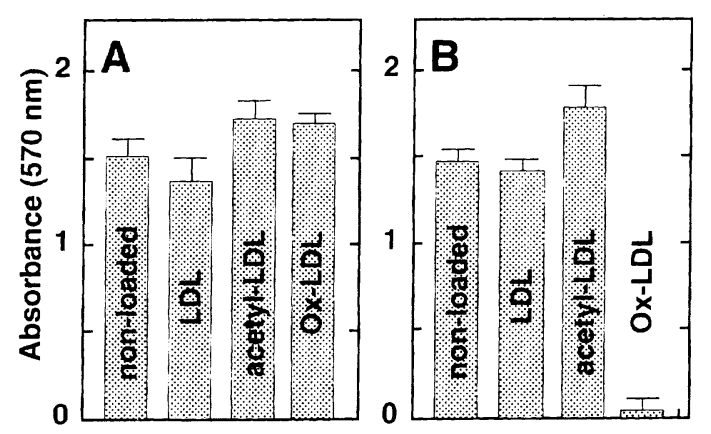

Fig. 2. Effects of Ox-LDL on cell viability of JO21b cells. JO21b $(\mathrm{A})$ and $\mathrm{J} 774(\mathrm{~B})$ cells $\left(5 \times 10^{3}\right)$ were plated in microplates and incubated in a final volume of $0.1 \mathrm{ml} \mathrm{RPMI} \mathrm{1,640}$ containing $10 \% \mathrm{NCS}$ with $0.1 \mathrm{mg} / \mathrm{ml}$ of Ox-LDL, acetyl-LDL, $\mathrm{LDL}$ or medium alone (non-loaded) for 7 days. Four hours before the termination of the experiment, $10 \mu \mathrm{l}$ of $5 \mathrm{mg} / \mathrm{ml}$ of MTT solution was added to each well. $150 \mu \mathrm{l}$ of $10 \%$ SDS in $0.01 \mathrm{M} \mathrm{HCl}$ was then added to each well and further incubated for $16 \mathrm{~h}$ to dissolve the blue formazan product. The absorbance was read with a multiwell spectrophotometer at $570 \mathrm{~nm}$. Data are representative of three separate experiments with duplicate wells.
Ctotoxic effects of 7-ketocholesterol, $t$-butyl hydroperoxide and lysophosphatidylcholine on JO21b Cells

The potential cytotoxic compounds of Ox-LDL include oxysterols $(23,29-31)$, lipid hydroperoxides (32-34) and lysophosphatidylcholines (35). Since we first hypothesized that an enzyme(s) involved in detoxification of the above compounds is overexpressed in JO21b cells, we examined the effects of these compounds on the cell viability of $\mathrm{JO} 21 \mathrm{~b}$ cells. As representatives of the three groups of the above cytotoxins, 7-ketocholesterol, tertiary-butyl ( $t$-butyl) hydroperoxide and palmitoyl-lysophosphatidylcholine were tested (Fig. 3). However, JO21b cells were apparently as sensitive as the parent cells to these compounds (28). Next we examined the combined effects of these compounds on JO21b cells. Again, there was no difference in the sensitivity between JO21b and parent $\mathbf{J 7 7 4}$ cells. It is therefore unlikely that the enzymes involved in detoxification of certain cytotoxic compounds of Ox-LDL are overexpressed in JO21b cells.

\section{Cellular interaction of Ox-LDL with JO21b cells}

To elucidate the cellular metabolism of Ox-LDL in macrophages, the interaction of Ox-LDL with JO21b cells

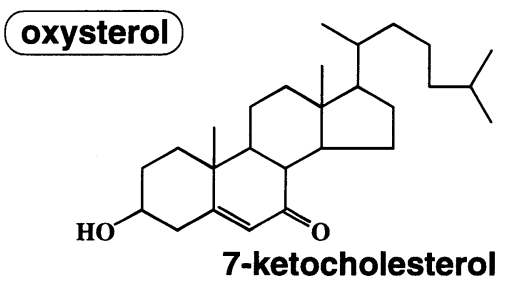

lipid hydroperoxide

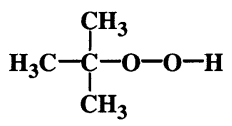

tertiary-butyl hydroperoxide

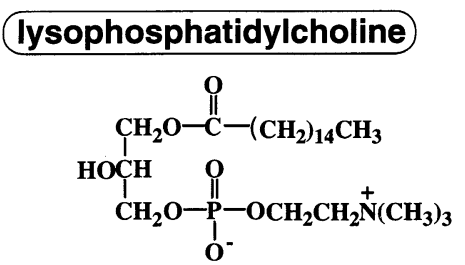

\section{palmitoyl-lysophosphatidylcholine}

Fig. 3. Chemical structure of 7-ketocholesterol, tertiarybutyl hydroperoxide and palmitoyl-lysophosphatidylcholine. The potential cytotoxic compounds of Ox-LDL are classified into oxysterols, lipid hydroperoxides and lysophosphatidylcholines. 7-Ketocholesterol and palmitoyl-lysophosphatidylcholine are representative cytotoxic moieties of OxLDL. Tertiary-butyl hydroperoxide is not a natural compound but an artificial water-soluble lipid hydroperoxide analog which is often used in cellular experiments. 


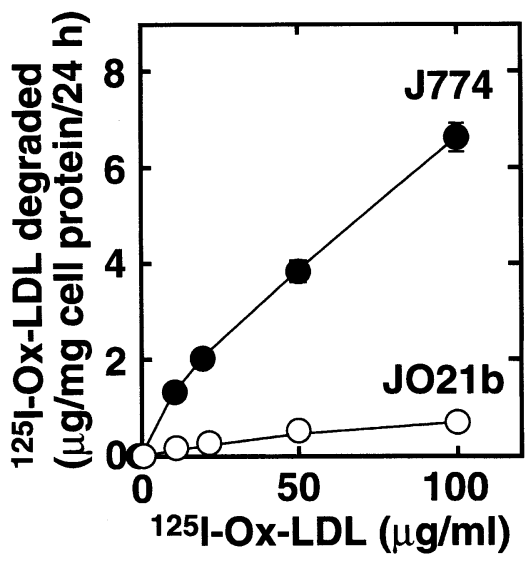

Fig. 4. Endocytic degradation of ${ }^{125}$-Ox-LDL by JO21b cells. JO21b cells or control J774 cells $\left(2 \times 10^{5}\right)$ in 24 -well plates (16-mm diameter) were incubated for $24 \mathrm{~h}$ at $37^{\circ} \mathrm{C}$ with the indicated concentrations of ${ }^{125} \mathrm{I}-\mathrm{Ox}$-LDL. The degradation of ${ }^{125}$ I-Ox-LDL by the cells was determined as $10 \%$ trichloroacetic acid-soluble radioactivity in the medium. Data are representative of three separate experiments with triplicate wells. SD values are small and within the symbols.

Table 2. Scavenger Receptor Families

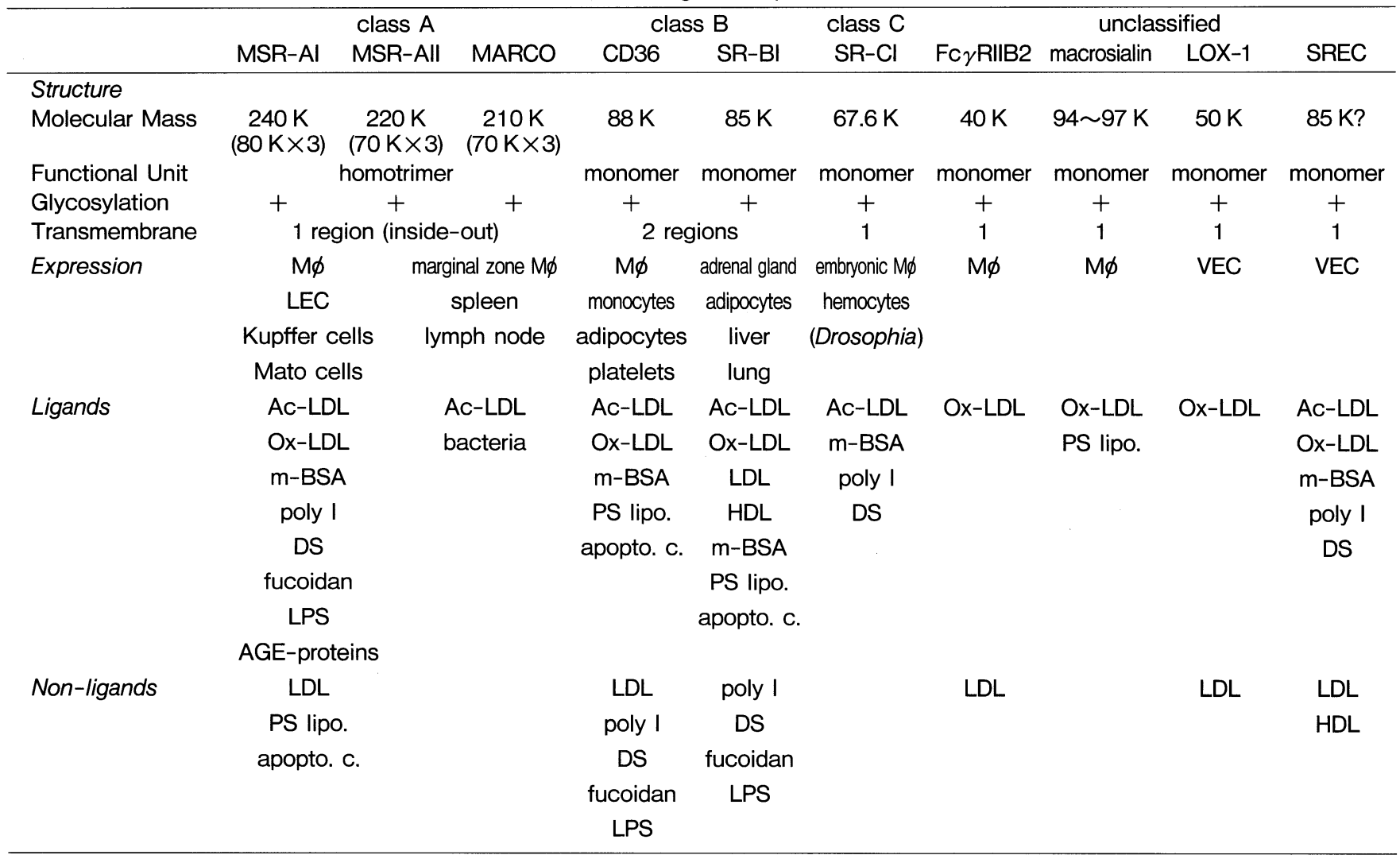

Based on the primary structures, scavenger receptor families are classified into class A (MSR-AI, MSR-All, and MARCO), class $\mathrm{B}$ (CD36 and SR-BI/CLA-1), class C (SR-Cl) and unclassified receptors (Fc $\gamma$ RIIB2, macrosialin/CD68, LOX-1 and SREC). This table indicates their structural information (molecular mass, functional unit, presence of glycosylation site, and number of transmembrane regions), expression (tissue and cell), and ligand specificity. Acetyl-LDL (Ac-LDL) is a common ligand for class $\mathrm{A}, \mathrm{B}$ and $\mathrm{C}$ receptors. Anionic phospholipid liposome such as phosphatidylserine liposome (PS lipo.) is not recognized by MSR-AI/All but recognized by class B receptors. In contrast, dextran sulfate (DS) and polyinoinic acid (poly I) are not recognized by class $B$ receptors but recognized by MSR-Al/All.

MSR indicate macrophage scavenger receptors; MARCO, macrophage receptor with collagenous structure; SREC, scavenger receptor expressed by endothelial cells ; $M \phi$, macrophages ; LEC, sinusodial liver endothelial cells ; Ac-LDL, acetylated LDL ; Ox-LDL, oxidized LDL; m-BSA, maleylated bovine serum albumin; poly I, polyinocinic acid; DS, dextran sulfate; LPS, lipopolysuccharide; AGE-proteins, advanced glycation end products-modified proteins; PS lipo., phosphatidylserine liposome ; apopto. c., apoptotic cells ; and VEC, vascular endothelial cells. 
was determined by cellular binding, cell-association and intracellular degradation. The total binding of ${ }^{125} \mathrm{I}-\mathrm{Ox}-$ LDL to JO21b cells at $0^{\circ} \mathrm{C}$ was reduced by $50 \%$ compared with that of $\mathrm{J} 774$ cells (28). The total degradation of ${ }^{125}$ Ox-LDL by JO21b cells in $24 \mathrm{~h}$ was also decreased by $80 \%$ compared with that by $\mathbf{J 7 7 4}$ cells (Fig. 4). Similarly, the total cellular association of ${ }^{125} \mathrm{~J}-\mathrm{Ox}$-LDL with JO21b cells was less than $20 \%$ of that with $\mathrm{J} 774$ cells (28). These results indicated that the scavenger receptor pathway is defective in $\mathrm{JO} 21$ cells.

\section{Ox-LDL receptors}

Several membrane proteins on macrophage cell surface are proposed to function as potential Ox-LDL receptors. These molecules include type I and type II class A macrophage scavenger receptors (MSR-Al/All) (36), MARCO (37), CD36 (38), SR-BI/CLA-1 (39), SR-Cl (40), Fc $\gamma$ RII-B2 (41), macrosialin/CD68 (42), LOX-1 (43), and SREC (44) (Table 2). Among these scavenger receptors, we focused on MSR-Al/All in the current study. According to a recent report by Lougheed et al. (45), endocytic uptake of Ox-LDL by peritoneal macrophages from MSR$\mathrm{Al} /$ All-knockout mice was decreased only by $30 \%$ compared to that with their wild-type macrophages, indicating endocytic uptake of Ox-LDL mainly depends on receptors other than MSR-AI/All. However, our previous studies clearly showed that the cell-association of OxLDL by MSR-Al/All-knockout macrophages was reduced by $>50-70 \%$ compared to wild-type $(46,47)$. This difference in contribution of MAR-Al/All to cellular uptake of Ox-LDL might be derived from differences in ligand preparations and/or culture conditions. However, all these reports suggest that $\mathrm{MSR}-\mathrm{Al} / \mathrm{All}$ is one of the major receptors for $\mathrm{Ox}-\mathrm{LDL}$ in murine macrophages.

\section{mRNA expression of MSR-Al/All in JO21b cells}

If $\mathrm{MSR}-\mathrm{Al} / \mathrm{All}$ plays a major role in the endocytic uptake of $\mathrm{Ox}-\mathrm{LDL}$, reduction in endocytic degradation of Ox-LDL in JO21b cells (Fig. 4) suggests a possible reduction in MSR-Al/All activity in these cells. Northern blot analysis was performed to examine MSR-Al/All expression at an mRNA level. The expression level of mRNA for both MSR-AI and MSR-All was lower by $70 \%$ in JO21b cells than in $\mathrm{J} 774$ cells (28), suggesting that resistance to Ox-LDL cytotoxicity, the characteristic phenotype of JO21b cells, has a functional link to the reduced expression of MSR-Al/All and a concomitant decrease in uptake of Ox-LDL.

\section{Cytotoxic Effect of Ox-LDL on Macrophages from MSR- Al/All-Knockout Mice}

In order to elucidate the correlation of reduced MSR$\mathrm{Al} /$ All activity to reduced sensitivity to the cytotoxic effect of Ox-LDL, we compared the sensitivity of peritoneal macrophages obtained from MSR-Al/All-knockout mice (47) with that of their wild-type littermates. As shown in
Fig. 5, incubation with $0.2 \mathrm{mg} / \mathrm{ml}$ of $\mathrm{Ox}$-LDL for $48 \mathrm{~h}$ caused total cell death of both wild-type and MSR-Al/ All-knockout macrophages. However, when incubated with $0.1 \mathrm{mg} / \mathrm{ml}$ of Ox-LDL, wild-type macrophages showed a $36.9 \%$ decrease in cell viability whereas knockout macrophages showed no change in cell viability (Fig. 5). These results clearly indicate that peritoneal macrophages from MSR-Al/All-knockout mice are more resistant to the cytotoxic effect of Ox-LDL than those from wild-type mice, suggesting that MSR-Al/All plays an enhancing role in the cytotoxic effect of Ox-LDL toward macrophages.

\section{Ox-LDL-Induced Macrophage Cell Death vs. Ox-LDL- Induced Macrophage Growth}

Proliferation of smooth muscle cells has been so far regarded as a critical step in the development of atherosclerosis (7). However, morphological studies have also demonstrated that macrophages or macrophage-derived foam cells proliferate in situ in atherosclerotic lesions (4850). Although the focus of this review is Ox-LDL-induced macrophage cell death, we reported previously that

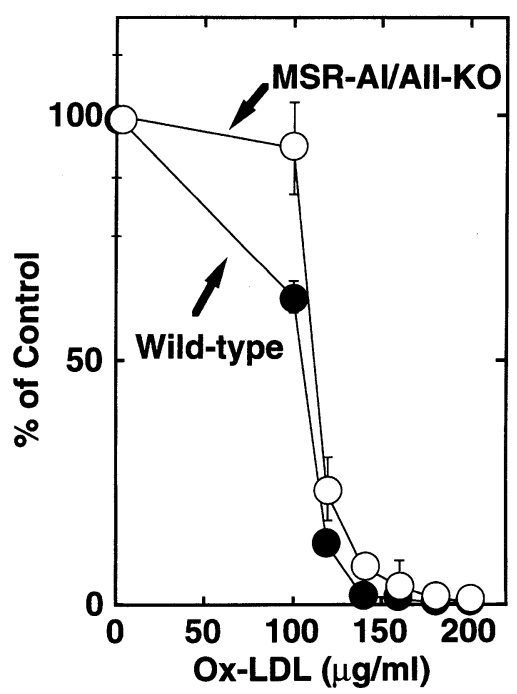

Fig. 5. Cytotoxic effect of Ox-LDL on peritoneal macrophages obtained from MSR-Al/All-knockout mice. Fifty micro liters of cell suspensions $\left(5 \times 10^{5}\right.$ cells) of peritoneal macrophages from MSR-Al/All-knockout mice and their wild-type littermates were dispersed in each well of 96-well tissue culture plates. To each well was added $50 \mu \mathrm{l}$ of OxLDL in RPMI 1640 to the indicated final concentrations, followed by further incubation for $48 \mathrm{~h}$ at $37^{\circ} \mathrm{C}$. The cell viability was determined by the MTT assay as described in the legend of Fig. 2. The results are expressed as percentages of the mean optical density at $570 \mathrm{~nm}$ when the concentration of Ox-LDL was zero. The $100 \%$ values were 0.152 in MSR-Al/All-knockout macrophages and 0.155 in wild-type macrophages. Data are representative of three separate experiments with quadruplicate wells. Bars represent SD. Where the error bars are not shown, the values are within the symbols. 
Ox-LDL also induces macrophage growth in mouse (51), human (52) and rat (53). In this process, endocytic uptake by MSR-Al/All of lysophosphatidylcholine of OxLDL plays an important role in the mitogenic effect of Ox$\operatorname{LDL}(46,54,55)$. It is interesting to note that Ox-LDLinduced macrophage growth shares a common mechanism with Ox-LDL-induced macrophage cell death, since both phenomena are enhanced by MSR-AI/All-mediated endocytic uptake of Ox-LDL.

\section{Conclusions}

Fig. 6 shows our conclusions. The potential cytotoxic compounds of Ox-LDL such as oxysterols, lipid hydroperoxides and lysophosphatidylcholines can be transferred to macrophages by at least two independent pathways. One is non-specific transfer of these toxic lipids to the plasma membrane by lipid exchange reaction. The other is receptor-mediated endocytic uptake of Ox-LDL through MSR-Al/All. Both pathways lead macrophages to necrotic and/or apoptotic death. Our recent study using macrophage cell genetics suggested that Ox-LDL-induced necrotic death of macrophages is enhanced by MSR-AI/All-mediated endocytic uptake of Ox-LDL (28).

Recently, Nagy et al. (56) have shown that lysosomal degradation of Ox-LDL leads to the release of oxidized linoleic acids such as 9-hydroxyoctadecadienoic acid (9HODE) and 13-hydroxyoctadecadienoic acid (13-HODE) through hydrolysis of oxidized cholesteryl linoleate. These oxidized fatty acids behave as the ligands for peroxisome proliferator activated receptor $\gamma(\mathrm{PPAR} \gamma)$ and increase CD36 expression in human monocytes and THP1 cells. The key finding of this report is that bioactive lipids are released from Ox-LDL through receptor-mediated endocytosis followed by lysosomal processing. Thus, it is interesting to hypothesize that cytotoxic lipids in Ox$\mathrm{LDL}$ are released through intracellular processing of $\mathrm{Ox}-$ LDL, increasing Ox-LDL cytotoxicity.

Finally, in vitro experiments using Ox-LDL often lead us to paradoxical conclusions on the atherogenicity of $\mathrm{Ox}$ LDL (57). As we mentioned above, Ox-LDL is able to induce macrophage proliferation (for review, see 55 ) as well as macrophage cell death (28). Moreover, lyso-PC, a major phospholipid in Ox-LDL, behaves as a cytotoxic compound (Hakamata et al., 1998) but also behaves as a mitogenic factor for macrophages $(46,54)$. It is unknown how Ox-LDL shows such paradoxical effects. This might be due, in part, to the differences in the cell types, culture conditions, concentrations of Ox-LDL, and/or physicochemical properties of each Ox-LDL preparation. Further

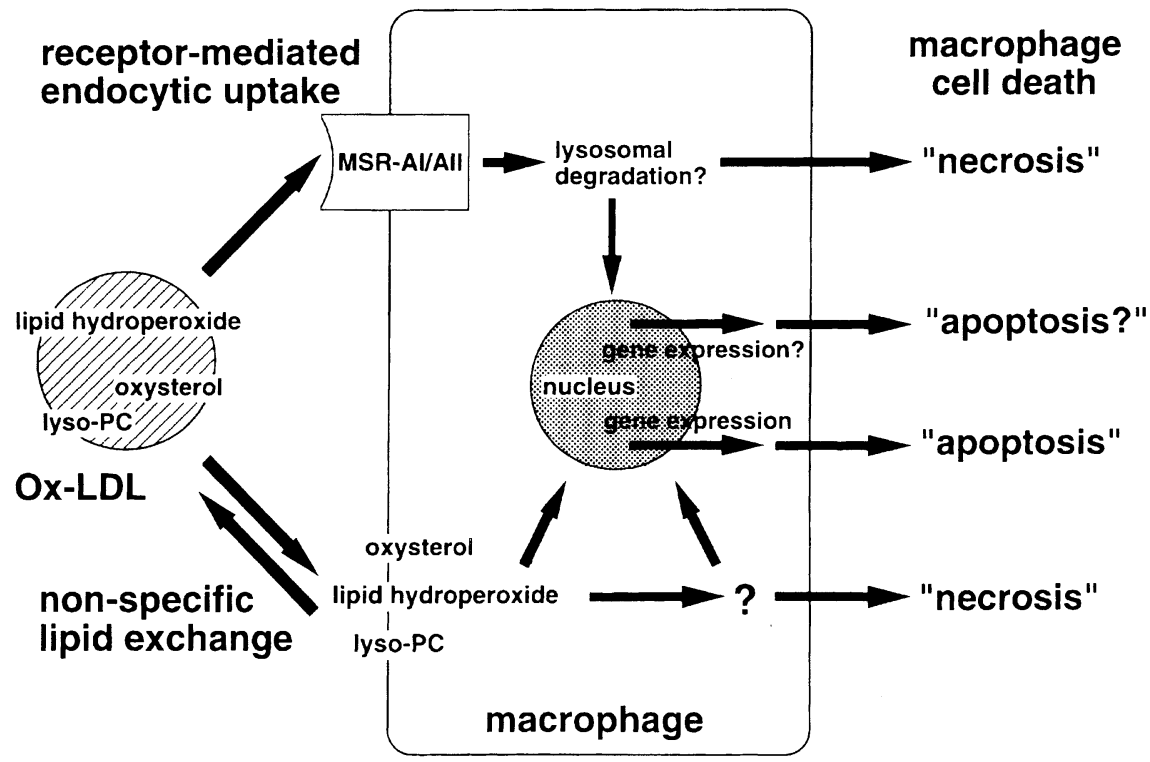

Fig. 6. Schematic representation of the enhancing effect of MSR-AI/All on Ox-LDL-induced cytotoxicity to macrophages. The potential cytotoxic compounds of Ox-LDL such as oxysterols, lipid hydroperoxides and lysophosphatidylcholines can be transferred to macrophages by at least two independent pathways. One pathway is receptor-mediated endocytic uptake of Ox-LDL through MSR-Al/All. Lysosomal delivery and processing of Ox-LDL produce several bioactive compounds which may enhance expression of apoptosis-related genes, leading macrophages to apoptosis. Macrophage necrosis is possibly enhanced by the MSR-Al/All-mediated endocytic uptake of the toxic compound of Ox-LDL. The other pathway is non-specific transfer of these toxic lipids to the plasma membrane by lipid exchange reaction. These toxic lipids or their unknown metabolites promote expression of several genes involved in apoptosis, which eventually leads macrophages to apoptotic cell death. At the same time, these toxic lipids may cause necrotic cell death of macrophages. 
studies are needed to address this issue.

Acknowledgments: We especially thank Dr. Michihiko Kuwano of the Department of Biochemistry, Kyushu University School of Medicine, for his kind and helpful advice on somatic cell genetics. We are grateful to Drs. Hirofumi Matsuda, Takeshi Biwa, Takashi Kawano, Takashi Kawasaki, Yuko Hasunuma, Guoping Wang, and Kyu Kyu Maung of our laboratory for their collaborative endeavor throughout this study. We are also grateful to Dr. Hiroshi Suzuki of Chugai Pharmaceutical Co. Ltd. and to Dr. Tatsuhiko Kodama of the Department of Molecular Biology and Medicine, Research Center for Advanced Science and Technology, University of Tokyo, for their generous gift of MSR-Al/All-knockout mice. This work was supported in part by Grants-in-Aids for Scientific Research (No. 09877200, 09770789, 10671077 and 10877179) from the Ministry of Education, Science, Sports and Cultures of Japan.

\section{References}

(1) Steinberg D, Parthasarathy S, Carew TE, Khoo JC, and Witztum JL: Modifications of low-density lipoprotein that increase its atherogenicity. $\mathrm{N}$ Engl J Med, 320 : 915-924, 1989

(2) Palinski W, Rosenfeld ME, Yla-Herttuala S, Gurtner GC, Socher SS, Butler SW, Parthasarathy S, Carew TE, Steinberg $D$, and Witztum JL: Low density lipoprotein undergoes oxidative modification in vivo. Proc Natl Acad Sci USA, 86: 1372-1376, 1989

(3) Yla-Herttuala S, Palinski W, Rosenfeld ME, Parthasarathy S, Carew TE, Butler S, Witztum JL, and Steinberg D : Evidence for the presence of oxidatively modified low density lipoprotein in atherosclerotic lesions of rabbit and man. J Clin Invest, 84 : 1086-1095, 1989

(4) Steinberg D: Lewis A. Conner memorial lecture; oxidative modification of LDL and atherosclerosis. Circulation, 95 : 1062-1071, 1997

(5) Chisolm GM : Cytotoxicity of oxidized lipoproteins. Curr Opin Lipidol, 2 : 311-316, 1991

(6) Mitchinson MJ, Hardwick SJ, and Bennett MR: Cell death in atherosclerotic plaques. Curr Opin Lipidol, 7 : 324-329, 1996

(7) Ross R: The pathogenesis of atherosclerosis: a perspective for the 1990s. Nature, 362: 801-809, 1993

(8) Brown MS and Goldstein JL: Lipoprotein metabolism in the macrophage; implications for cholesterol deposition in atherosclerosis. Annu Rev Biochem, 52: 223-261, 1983

(9) Mori T, Takahashi K, Naito M, Kodama T, Hakamata H, Sakai M, Miyazaki A, Horiuchi S, and Ando M: Endocytic pathways of scavenger receptors via trans-Golgi system in bovine alveolar macrophages. Lab Invest, 71 : 409-416, 1994

(10) Liscum L and Underwood KW : Intracellular cholesterol transport and compartmentation. J. Biol. Chem, 270: 15443-15446, 1995

(11) Chang TY, Chang CCY, and Cheng D: Acyl-coenzyme A : cholesterol acyltransferase. Annu Rev Biochem,
$66: 613-638,1997$

(12) Brown MS, Ho YK, and Goldstein JL: The cholesteryl ester cycle in macrophage foam cells : continual hydrolysis and re-esterification of cytoplasmic cholesteryl esters. J Biol Chem, 255: 9344-9352, 1980

(13) Hakamata $H$, Miyazaki A, Sakai M, Suginohara $Y$, Sakamoto $\mathrm{Y}$, and Horiuchi S: Species difference in cholesteryl ester cycle and HDL-induced cholesterol efflux from macrophage foam cells. Arterioscler Thromb, 14 : 18601865, 1994

(14) Geng YJ and Libby P: Evidence for apoptosis in advanced human atheroma; colocalization with interleukin-1 $\beta$-converting enzyme. Am J Pathol, 147 : 251266, 1995

(15) Aqel NM, Ball RY, Waldmann $\mathrm{H}$, and Mitchinson MJ : Identification of macrophages and smooth muscle cells in human atherosclerosis using monoclonal antibodies. J Pathol, 146: 197-204, 1985

(16) Quinn MT, Parthasarathy S, Fong GL, and Steinberg D : Oxidatively modified low density lipoprotein : A potential role in recruitment and retention of monocytes/macrophages during atherogenesis. Proc Natl Acad Sci USA, 84: 2995-2998, 1987

(17) Berliner JA, Territo MC, Sevanian A, Ramin S, Kim JA, Bamshad B, Esterson M, and Fogelman AM : Minimally modified low density lipoprotein stimulates monocyte endothelial interactions. J Clin Invest, 85 : 1260-1266, 1990

(18) Frostegård J, Nilsson J, Haegarstrand A, Hamsten A, Wigzell $H$, and Gidlund $M$ : Oxidized low-density lipoprotein induces differentiation and adhesion of human monocytes and the monocytic cell line U937. Proc Natl Acad Sci USA, 87 : 904-908, 1990

(19) Quinn MT, Parthasarathy S, and Steinberg D: Endothelial cell-derived chemotactic activity for mouse peritoneal macrophages and the effects of modified forms of low density lipoprotein. Proc Natl Acad Sci USA, 82 : 5949-5953, 1985

(20) Marchant CE, Law NS, van der Veen C, Hardwick SJ, Carpenter $\mathrm{KLH}$, and Mitchinson MJ : Oxidized low-density lipoprotein is cytotoxic to human monocyte-macrophages: protection with lipophilic antioxidants. FEBS Lett, 358: 175-178, 1995

(21) Henriksen T, Evensen SA, and Carlander B: Injury to human endothelial cells in culture induced by low density lipoproteins. Scand J clin Lab Invest, 39: 361-368, 1979

(22) Hessler JR, Robertson Jr. AL, and Chisolm GM : LDLinduced cytotoxicity and its inhibition by HDL in human vascular smooth muscle and endothelial cells in culture. Atherosclerosis, 32 : 213-229, 1979

(23) Hughes $H$, Mathews B, Lenz ML, and Guyton JR: Cytotoxicity of oxidized LDL to porcine aortic smooth muscle cells is associated with the oxysterols 7-ketocholesterol and 7-hydroxycholesterol. Arteiroscler Thromb, 14 : 1177-1185, 1994

(24) Reid VC, Hardwick SJ, and Mitchinson MJ : Fragmentation of DNA in $\mathrm{P}_{388 \mathrm{D}_{1}}$ macrophages exposed to oxidised low-density lipoprotein. FEBS Lett, 332 : 218-220, 1993

(25) Harada K, Ishibashi S, Miyashita T, Osuga J, Yagyu H, Ohashi $\mathrm{K}$, Yazaki $\mathrm{Y}$, and Yamada $\mathrm{N}$ : Bcl-2 protein inhibits oxysterol-induced apoptosis through suppressing CPP32-mediated pathway. FEBS Lett, 411: 63-6, 
1997

(26) Yuan XM, Li W, Olsson AG, and Brunk UT: The toxicity of macrophages of oxidized low-density lipoprotein is mediated through lysosomal damage. Atherosclerosis, 133: 153-161, 1997

(27) Kinscherf R, Claus R, Wagner M, Gehrke C, Kamencic $H$, Hou D, Nauen O, Schmiedt W, Kovacs G, Pill J, Metz J, and Deigner HP: Apoptosis caused by oxidized LDL is manganese superoxide dismutase and p53 dependent. FASEB J, 12 : 461-467, 1998

(28) Hakamata $H$, Miyazaki A, Sakai M, Matsuda $H$, Suzuki $H$, Kodama $\mathrm{T}$, and Horiuchi $\mathrm{S}$ : Isolation of macrophage-like cell mutants resistant to the cytotoxic effect of oxidized low density lipoprotein. J Lipid Res, 39 : 482-494, 1998

(29) Guyton JR, Black BK, and Seidel CL: Focal toxicity of oxysterols in vascular smooth muscle cell culture: a model of the atherosclerotic core region. Am J Pathol, 137 : 425-434, 1990

(30) Chisolm GM, Ma G, Irwin KC, Martin LL, Gunderson KG, Linberg LF, Morel DW, and DiCorleto PE : $7 \beta$-hydroperoxycholest-5-en-3 $\beta$-ol, a component of human atherosclerotic lesions, is the primary cytotoxin of oxidized human low density lipoprotein. Proc Natl Acad Sci USA, 91: 11452-11456, 1994

(31) Colles SM, Irwin KC, and Chisolm GM : Roles of multiple oxidized LDL lipids in cellular injury: dominance of $7 \beta-$ hydroperoxycholesterol. J Lipid Res, 37 : 2018-2208, 1996

(32) Thomas JP, Geiger PG, and Girotti AW : Lethal damage to endothelial cells by oxidized low density lipoprotein : role of selenoperoxide in cytoprotection against lipid hydroperoxide- and iron-induced reactions. J Lipid Res, 34 : 479-490, 1993

(33) Kuzuya M, Naito M, Funai C, Hayashi T, Asai K, and Kuzuya $F$ : Lipid peroxide and transition metals are required for the toxicity of oxidized low density lipoprotein to cultured endothelial cells. Biochim Biophys Acta, 1096: 155-166, 1991

(34) Naito M, Yamada K, Hayashi T, Asai K, Yoshimine N, and Iguchi A: Comparative toxicity of oxidatively modified low-density lipoprotein and lysophosphatidylcholine in cultured vascular endothelial cells. Heart Vessels, 9 : 183-187, 1994

(35) Chen Y, Morimoto S, Kitano S, Koh E, Fukuo K, Jiang B, Chen S, Yasuda O, Hirotani A, and Ogihara T: Lysophosphatidylcholine cause $\mathrm{Ca}^{2+}$ influx, enhanced DNA synthesis and cytotoxicity in cultured vascular smooth muscle cells. Atherosclerosis, 112: 69-76, 1995

(36) Kodama T, Freeman M, Rohrer L, Zabrecky J, Matsudaira $P$, and Krieger $M$ : Type I macrophage scavenger receptor contains $\alpha$-helical and collagen-like coiled coils. Nature, 343 : 531-535, 1990

(37) Elomaa O, Kangas M, Sahlberg C, Tuukkanen J, Sormunen R, Liakka A, Thesleff I, Kraal G, and Tryggvason $\mathrm{K}$ : Cloning of a novel bacteria-binding receptor structurally related to scavenger receptors and expressed in a subset of macrophages. Cell, 80: 603-609, 1995

(38) Endemann G, Stanton LW, Madden KS, Bryant CM, Tyler White R, and Protter AA. : CD36 is a receptor for oxidized low density lipoprotein. J Biol Chem, 268: 11811-11816, 1993

(39) Acton SL, Scherer PE, Lodish HF, and Krieger M: Expression cloning of SR-BI, a CD36-related class $\mathrm{B}$ scavenger receptor. J Biol Chem, 269: 21003-21009, 1994

(40) Pearson A, Lux A, and Krieger M : Expression cloning of dSR-Cl, a class $\mathrm{C}$ macrophage-specific scavenger receptor from Drosophila melanogaster. Proc Natl Acad Sci USA, 92 : 4056-4060, 1995

(41) Stanton LW, Tyler White R, Bryant CM, Protter AA, and Endemann $\mathrm{G}$ : A macrophage $\mathrm{Fc}$ receptor for IgG is also a receptor for oxidized low density lipoprotein. J Biol Chem, 267: 22446-22451, 1992

(42) Ramprasad MP, Fischer W, Witztum JL, Sambrano GR, Quehenberger O, and Steinberg D: The 94- to 97-kDa mouse macrophage membrane protein that recognizes oxidized low density lipoprotein and phosphatidylserinerich liposomes is identical to macrosialin, the mouse homologue of human CD68. Proc Natl Acad Sci USA, 92: 9580-9584, 1995

(43) Sawamura T, Kume N, Aoyama T, Moriwaki H, Hoshikawa H, Aiba Y, Tanaka T, Miwa S, Katsura Y, Kita T, and Masaki $\mathrm{T}$ : An endothelial receptor for oxidized lowdensity lipoprotein. Nature, 386: 73-77, 1997

(44) Adachi $\mathrm{H}$, Tsujimoto $\mathrm{M}$, Arai $\mathrm{H}$, and Inoue $\mathrm{K}$ : Expression cloning of a novel scavenger receptor from human endothelial cells. J Biol Chem, 272: 31217-31220, 1997

(45) Lougheed M, Lum CM, Ling W, Suzuki H, Kodama T, and Steinbrecher $U$ : High affinity saturable uptake of oxidized low density lipoprotein by macrophages from mice lacking the scavenger receptor class A type I/II. J Biol Chem, 272 : 12938-12944, 1997

(46) Sakai M, Miyazaki A, Hakamata H, Kodama T, Suzuki H, Kobori S, Shichiri M, and Horiuchi S: The scavenger receptor serves as a route for internalization of lysophosphatidylcholine in oxidized low density lipoprotein-induced macrophage proliferation. J Biol Chem, 271: 27346-27352, 1996

(47) Suzuki H, Kurihara Y, Takeya M, Kamada N, Kataoka M, Jishage K, Ueda O, Sakaguchi H, Higashi T, Suzuki T, Takashima Y, Kawabe Y, Cynshi O, Wada Y, Honda M, Kurihara $\mathrm{H}$, Aburatani $\mathrm{H}$, Doi T, Matsumoto A, Azuma S, Noda T, Toyoda Y, Itakura H, Yazaki Y, Horiuchi S, Takahashi K, Kruijt JK, van Berkel TJC, Steinbrecher UP, Ishibashi S, Maeda N, Gordon S, and Kodama T: A role for macrophage scavenger receptors in atherosclerosis and susceptibility to infection. Nature, 386: 292-296, 1997

(48) Gordon D, Reidy MA, Benditt EP, and Schwartz SM : Cell proliferation in human coronary arteries. Proc Natl Acad Sci USA, 87 : 4600-4604, 1990

(49) Rosenfeld ME and Ross R: Macrophage and smooth muscle cell proliferation in atherosclerotic lesions of WHHL and comparably hypercholesterolemic fat-fed rabbits. Arteriosclerosis, 10 : 680-687, 1990

(50) Spagnoli LG, Orlandi A, and Santeusanio G : Foam cells of the rabbit atherosclerotic plaque arrested in metaphase by colchicine show a macrophage phenotype. Atherosclerosis, 88: 87-92, 1991

(51) Yui S, Sasaki T, Miyazaki A, Horiuchi S, and Yamazaki $\mathrm{M}$ : Induction of murine macrophage growth by modified LDLs. Arterioscler Thromb, 13: 331-337, 1993

(52) Sakai M, Miyazaki A, Hakamata H, Sato $Y$, Matsumura T, Kobori S, Shichiri M, and Horiuchi S : Lysophosphatidylcholine potentiates the mitogenic activity of modified low density lipoproteins for human monocyte-derived macro- 
phages. Arterioscler Thromb Vasc Biol, 16: 600-605, 1996

(53) Sato Y, Kobori S, Sakai M, Yano T, Higashi T, Matsumura T, Morikawa W, Terano T, Miyazaki A, Horiuchi S, and Shichiri $M$ : Lipoprotein(a) induces cell growth in rat peritoneal macrophages through inhibition of transforming growth factor $-\beta$ activation. Atherosclerosis, 125: 15-26, 1996

(54) Sakai M, Miyazaki A, Hakamata H, Sasaki T, Yui S, Yamazaki M, Shichiri M, and Horiuchi S: Lysophosphatidylcholine plays an essential role in the mitogenic effect of oxidized low density lipoprotein on murine macrophages. J Biol Chem, 269: 31430-31435, 1994
(55) Sakai M, Shichiri M, Hakamata $H$, and Horiuchi S: Endocytosed lysophosphatidylcholine, through the scavenger receptor, plays an essential role in oxidized lowdensity lipoprotein-induced macrophage proliferation. Trends Cardiovasc Med, 8: 119-124, 1998

(56) Nagy L, Tontonoz P, Alvarez JGA, Chen H, and Evans RM : Oxidized LDL regulates macrophage gene expression through ligand activation of PPAR $\gamma$. Cell, 93: 229-240, 1998

(57) Elinder LS and Walldius G : Antioxidants and atherosclerosis progression; unresolved questions. Curr Opin Lipidol, 5 : 265-268, 1994 